\title{
A Climatology and Extreme Value Analysis of Large Hail in China
}

\author{
XIANG Ni \\ Chongqing Jinfo Mountain Field Scientific Observation and Research Station for Kaster Ecosystem, School of Geographical \\ Sciences, Southwest University, Chongqing, and Department of Atmospheric and Oceanic Sciences, School of Physics, \\ Peking University, Beijing, China \\ ANDREAS MUEHLBAUER \\ FM Global, Research Division, Norwood, Massachusetts \\ JOHN T. ALLEN \\ Department of Earth and Atmospheric Sciences, Central Michigan University, Mt. Pleasant, Michigan \\ QINGHONG ZHANG \\ Department of Atmospheric and Oceanic Sciences, School of Physics, Peking University, Beijing, China \\ JIWEN FAN \\ Atmospheric Science and Global Change Division, Pacific Northwest National Laboratory, Richland, Washington
}

(Manuscript received 31 August 2019, in final form 23 January 2020)

\begin{abstract}
Hail size records are analyzed at 2254 stations in China and a hail size climatology is developed based on gridded hail observations for the period 1960-2015. It is found that the annual percentiles of hail size records changed sharply and national-wide after 1980, therefore two periods, 1960-79 and 1980-2015, are studied. There are some similarities between the two periods in terms of the characteristics of hail size such as the spatial distribution patterns of mean annual maximum hail size and occurrence week of annual maximum hail size. The 1980-2015 period had higher observation density than the 1960-79 period, but showed smaller mean annual maximum hail size, especially in northern China. In the majority of grid boxes, the annual maximum hail size experienced a decreasing trend during the 1980-2015 period. A Gumbel extreme value model is fitted to each grid box to estimate the return periods of maximum hail size. The scale and location parameter of the fitted Gumbel distributions are higher in eastern China than in western China, thereby reflecting a greater likelihood of large hail in eastern China. In southern China, the maximum hail size exceeds $127 \mathrm{~mm}$ for a 10 -yr return period, whereas in northern China maximum hail size exceeds this threshold for a 50-yr return period. The Gumbel model is found to potentially underestimate the maximum hail size for certain return periods, but provides a more informed picture of the spatial distribution of extreme hail size and the regional differences.
\end{abstract}

\section{Introduction}

Hail is one of the main natural hazards in China and it is the second most frequent cause for natural catastrophes after floods (Guan et al. 2014). In 2012 and 2013, hail events caused approximately 31 billion CNY (4.5 billion USD) and 14 billion CNY ( 2 billion USD) direct economic losses in China (Guan et al. 2014).

Corresponding author: Qinghong Zhang, qzhang@pku.edu.cn
The majority of losses are caused by the most severe convective storms with hailstones exceeding $20 \mathrm{~mm}$ (Berthet et al. 2013). For example, a single severe hailstorm that occurred in northern China caused 430 million CNY (60 million USD) of economic losses on 11 September 2016 (Ministry of Civil Affairs of the PRC 2016). A significant portion of these economic losses stem from agriculture, as crops are especially vulnerable to hail damage that can originate from either wind-driven hail, large hail or large volumes of 
smaller hail (Changnon et al. 2001). Towery et al. (1976) for example found that wind-driven hail loses could be 3-12 times greater than where crops were shielded from the wind. Yue et al. (2019) used field observation to investigate the relationship between cotton vulnerability and hail properties on a private farmland in China's Hebei province. They found that crop damage is significantly related to hail size and hail fall density but is more sensitive to hail diameter than hail fall density, which suggests hail size is a viable indicator of hail-induced damage. These socioeconomic impacts motivate an investigation of the frequency, size and spatial distributions, and return periods of extremely large hail in China.

A number of studies have considered hail size in China, with the first by Liu and Tang (1966). Subsequently, $\mathrm{Xu}$ (1983) discussed hail size distributions using data collected as part of several field campaigns, which mainly focused on the microphysical characteristics of hailstones. Recently, better hail observations have made it possible to study the hail size climatology of China and trends in hail size in the context of climate change. Manually compiled hail size records in four provinces were used by Xie et al. (2010) to investigate long-term trends of hail size in China for the first time, but no significant trends were identified. Using an expanded record from 2254 observer-staffed weather stations, X. Li et al. (2018) analyzed hail size characteristics in China focusing on the spatial distribution and diurnal cycle. Typically, hail (defined here as particles with diameter $\geq 2 \mathrm{~mm}$ ) occurrence was found to increase with elevation while mean hail size was found to decrease (X. Li et al. 2018). Larger hail was mostly found to occur at lower elevations such as the southern mountainous and northwest regions of China. Using the same data, $\mathrm{Ni}$ et al. (2017b) investigated the temporal trend of hail size in different regions of China. Since 1980, the probability density function of hail size in three selected regions (separated by station elevation $>2000,500-2000$, and $<500 \mathrm{~m}$ ) was found to shift to smaller sizes and the mean annual size of large hail showed a decreasing trend. While the existing body of research provides a fundamental understanding of the hail size climatology in China, it does not explore the likelihood of large hail size occurrence and extreme events.

Research on hail occurrence and size has become a topic of increasing focus over the years (Bardsley 1990; Cao 2008; Fraile et al. 2003; Dessens et al. 2015; Allen et al. 2017). However, inconsistencies in hail observation networks and reporting practices around the globe have made it difficult to compare the climatology of hail among regions using these observations (Allen et al. 2020). In a recent review, Punge and Kunz (2016) described hail observations in Europe, and developed a composite map of hail occurrence by combining direct and remotely sensed observations. Other approaches have taken a similar route to assess the likelihood of large hail. For example, Allen et al. (2015a) built an empirical model using an environmental parameter proxy to describe the frequency of hail occurrence (size $\geq 25 \mathrm{~mm}$ ). Using U.S. hail size reports, Allen et al. (2017) explored the spatial distribution and return levels for hail greater than a given hail size. Extending the environmental parameter methodology, Prein and Holland (2018) utilized severe hail (size $\geq 25 \mathrm{~mm}$ ) reports in the continental United States (CONUS), Australia, and Europe together with $0.75^{\circ} \times 0.75^{\circ}$ ERAInterim reanalysis to estimate the frequency of hail occurrence globally. However, the relationship between a favorable environment for hail and hail occurrence may not be globally consistent, which may be one reason why the projected global hail probability derived from hail environments differs from the results based on spaceborne precipitation radar and microwave observations (Bang and Cecil 2019; Cecil and Blankenship 2012; Ni et al. 2017a). These remote sensing methods identify higher frequency around the equator, contrasting the maximum around $10^{\circ} \mathrm{N}$ identified by studies based on hail environments (Prein and Holland 2018). However, hail climatologies based on spaceborne observations are also subject to uncertainties and are known to overestimate in the near tropics, where melting rates and high freezing levels may preclude smaller hailstones reaching the ground (Ferraro et al. 2015; Ni et al. 2017a; Prein and Holland 2018).

To predict the rare but extreme events in a certain period, generalized extreme value (GEV) distributions are often utilized (Jenkinson 1955). The family of GEV distributions is generally divided into three kinds of distributions namely: the Gumbel, Frechet, and Weibull families, depending on the value of the shape parameter. The shape parameter characterizes the statistical tailing behavior of the extremes. For extreme wind speeds, generalized Pareto distribution (GPD) and GEV have been used (Palutikof et al. 1999; Pavia and O'Brien 1986). Palutikof et al. (1999) reviewed the application of GPD and GEV for the study of extreme wind speeds and concluded that the GEV Type I (Gumbel) distribution has advantages in the fitting procedure because only two instead of three distribution parameters need to be estimated, which often leads to more stable results. Weibull distributions have been used for extreme wind speeds over the ocean (Pavia and O'Brien 1986), while Frechet distributions have been applied in studies of extreme rainfall (Coles 2001). Nevertheless, few efforts have applied extreme value modeling to study hail size extremes. Using hail observations from a large network 
of hail pad stations in France, Fraile et al. (2003) used the Gumbel distribution to describe expected hail size based on the annual maximum value in different regions and found different return periods in coastal and inland regions. Allen et al. (2017) also applied the Gumbel distribution to investigate annual maximum hail size based on time series of annual maxima in the United States. Given these successful applications of Gumbel distributions in the past, we aim to apply the extreme value model to the estimation of return periods for hail size in grid boxes based on the station-based hail size records in China.

This paper is organized in the following sections: the data and basic methodology are described in section 2 . The analysis for extreme hail size during the time periods before and after 1980 will be presented in the first part of section 3. The second part of section 3 discusses how the extreme value modeling is used to assess the occurrence probability of extreme hail size. A summary and conclusions are given in section 4.

\section{Data and method}

Hail data for China were compiled from observations provided by the National Meteorological Information Center (NMIC) and include hail records from 2254 stations for the period 1960-2015. These data include information for hail occurrence, maximum hail size (in units of $\mathrm{mm}$ ) for each hailstorm, which can either be measured or visually estimated by trained observers, time of occurrence and other fields. The routine observation not only recorded hail that occurred around the weather station but also recorded hail reported in the same administrative region, which is often reported by public or newspaper. The administrative regions could be located in different grid boxes and in this situation the location of the weather station is used to assign the hail size report. In this research, only observations that have hail size information were considered after the following quality control filter. In some cases, there are multiple hailfalls and several maximum hail size observations at a station in a single day. In this situation, the maximum hail size among these records is selected as the maximum hail size for this day. Records with hail size less than $2 \mathrm{~mm}$ or larger than $300 \mathrm{~mm}$ were removed in the analysis based on several factors. There are some records with size less than $2 \mathrm{~mm}$, which is inconsistent with Chinese surface meteorological observation manual that requires only solid precipitation particle with diameter larger than or equal to $2 \mathrm{~mm}$ to be recorded as hail (CMA 2007). The choice to exclude these records less than $2 \mathrm{~mm}$ has no bearing on the results of this study because it does not affect the maximum hail size over an annual time period. Note that the CMA's definition of hail is different from the definition used by the American Meteorological Society, which defines hail as frozen precipitation larger than $5 \mathrm{~mm}$ (American Meteorology Society 2012). During 1960-2015, there are also two records with diameter larger than or equal to $300 \mathrm{~mm}$, which occurred in southern China. With limited observational records to corroborate these reports, it is difficult to validate the accuracy of the two records. To provide context, these extreme outliers would be two of the largest stones ever recorded globally. Sensitivity testing of fitted extreme value model suggests that their inclusion caused return levels in southern China to depart significantly from those in other regions (not shown). On this basis, and due to the uncertainty about the measured size of these stones, hail size records larger than or equal to $300 \mathrm{~mm}$ are excluded for this analysis. However, five other records, one $200 \mathrm{~mm}$ record and four $250 \mathrm{~mm}$ records have been included in the analysis as some of them are cross verified from newspaper reports. One field survey was also conducted by a group led by corresponding author in 2016 and one $250 \mathrm{~mm}$ record in Guangdong Province was verified by local meteorological officer and farmers. We note that these four $250 \mathrm{~mm}$ hailstones are larger than the official $203 \mathrm{~mm}$ (8 in.) world record hailstone found in Vivian, South Dakota, in 2010, suggesting that the current record is unlikely to represent the upper limit for hail size from observations. For all hail sizes larger than $100 \mathrm{~mm}$, reports were validated against other resources such as newspapers. The net result is an archive of 70544 hail size reports across China from 1960 to 2015.

The observation regulation of hail size records was renewed after 1980, and a higher percentage of hail size was recorded. To avoid potential discontinuities and distinguish between the different characteristics of the hail climatology before and after 1980, this study divided the full observational record into two periods: 1960-79 and 1980-2015. The statistical characteristics of the observations for the respective periods are shown in Table 1. Most notably, the percentage of large hail $(20 \mathrm{~mm})$ occurrence among all hail occurrence dropped from $30 \%$ (before 1980) to $5.3 \%$ (after 1980). This would suggest that two potential explanations are that the observational guidelines became stricter after 1980, increasing the number of hail reports with size, thereby reducing the fractional percentage of larger hail, or alternatively excluding more errant large hail reports. This increases the likelihood of reporting large hail, despite the large distances between stations. The maximum hail size at these weather stations during 19602015 are shown in Fig. 1. Furthermore, station density in each $2.5^{\circ}$ grid box of the two periods is presented in 
TABLE 1. Statistical parameters of hail size records during 1960-79 and 1980-2015. Large hail represents hail record with diameter greater than or equal to $20 \mathrm{~mm}$.

\begin{tabular}{lcr}
\hline \hline & $1960-79$ & $1980-2015$ \\
\hline Station number & 1560 & 2236 \\
Hail size records number & 5731 & 64813 \\
Large hail size number & 1720 & 3443 \\
Grids number with record for at least & 88 & 152 \\
$\quad \begin{array}{l}10 \text { years } \\
\text { Grids number with at least 5 record for at } \\
\quad \text { least 10 years }\end{array}$ & 17 & 107 \\
\hline
\end{tabular}

Figs. 2a and 2b, respectively. One station in Figs. 2a and $2 b$ represents one administrative region with hail reports. More stations in the second period provides a wider spatial area that can be considered. This larger grid also ensures that multiple stations are sampled within each grid box. Considering the limited number of hail reports, temporal variations in the number of observing stations, and sampling issues for large hailstones (shown in Table 1 ), $2.5^{\circ}$ grid boxes are used. This binning procedure ensures sufficiently long data records and allows for a more robust estimation of Gumbel distribution parameters from observations. Note that only stations with at least one hail size report during the study period are considered. Overall, there is a substantial increase in station density after 1980 with large increases over northern China. Given the relative sparsity of population, the station density in western China is much smaller than in eastern China. Although the Tibetan Plateau (TP) has the highest hail occurrence
(Zhang et al. 2008), the station density over TP is considerably lower than in the more populated areas of eastern China.

The Gumbel model is fitted using annual maxima of daily maximum hail size consisting of the largest hail size in each respective grid in any given year and is fitted under an assumption of stationarity. For the following analysis, a maximum likelihood estimator (MLE) was used to determine the two parameters (location $\mu$ and scale $\sigma$ ) of the Gumbel distribution (Coles 2001):

$$
F(x)=\exp \left\{-\exp \left[-\left(\frac{x-\mu}{\sigma}\right)\right]\right\}
$$

Fitting is accomplished using MATLAB packages. Function EVFIT is used to estimate the extreme value parameters and on this basis, EVINV is used to calculate return levels and periods.

\section{Results}

\section{a. Gridded hail size climatology}

Comparing the gridded maximum hail size between the two selected periods (Fig. 3) illustrates a similar spatial pattern, despite the obvious differences in the number of stations and the increasing number of observations after 1980. The largest hail occurs in southern China, especially in the southeast. Comparing the two periods, the overall maximum hail size in the second period is significantly larger than the first period. This suggests that the increased density of stations taking

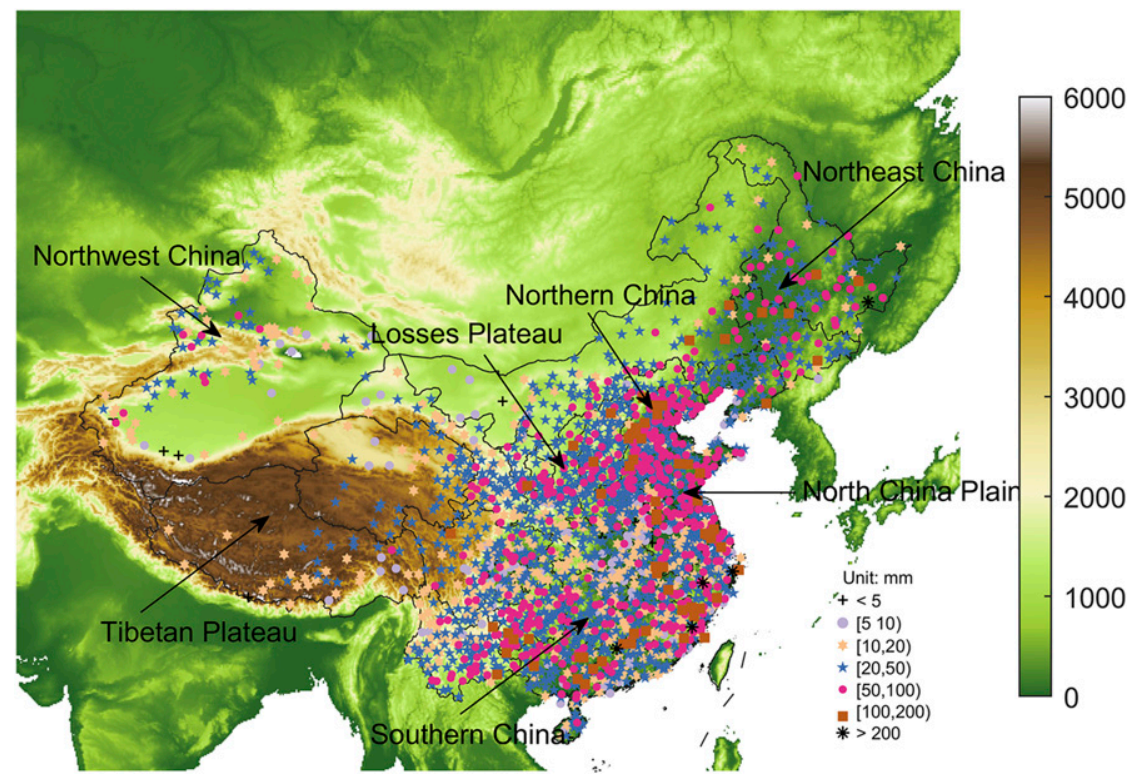

FIG. 1. Topography of China and observed maximum hail size at each station during the period 1960-2015. 

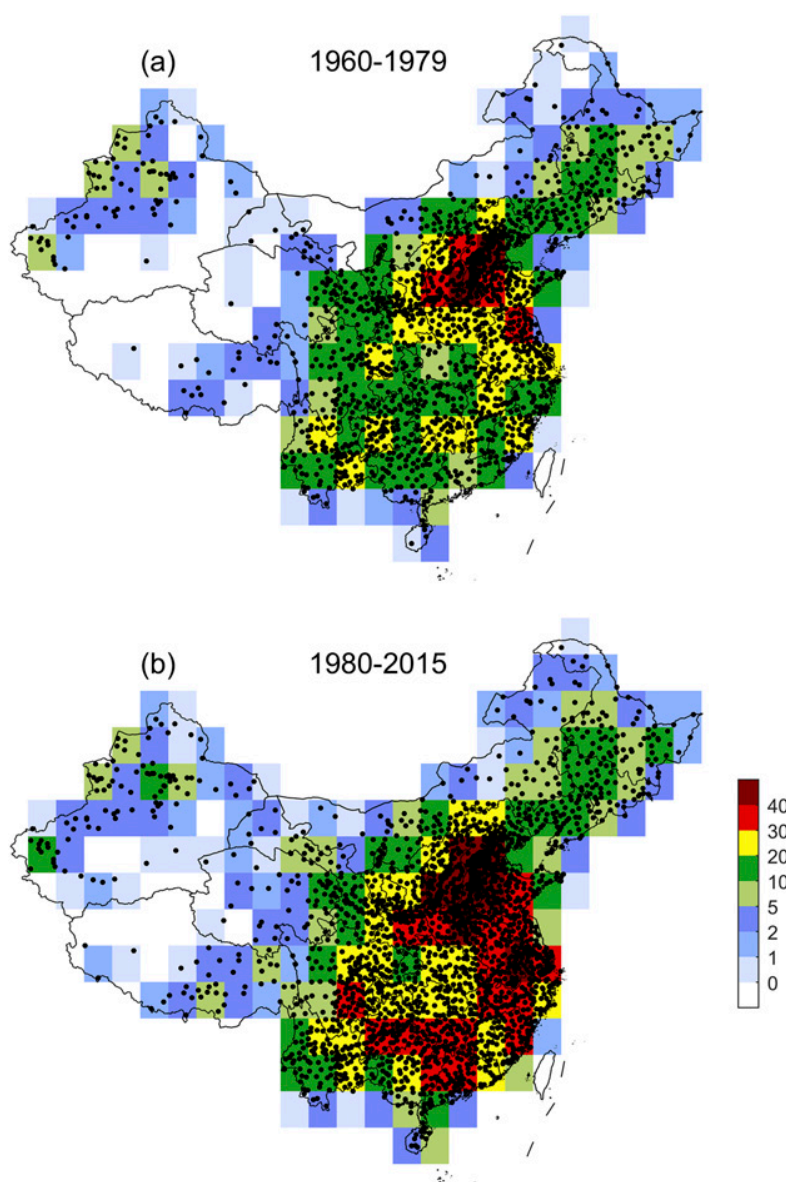

FIG. 2. Stations with at least one hail size record during (a) 1960 79 and (b) 1980-2015. Station locations (dots) and station density (color shading) are shown for each $2.5^{\circ}$ by $2.5^{\circ}$ grid box.

observations does have some impacts on the maximum observed hail size, with an increased number of grids observing maxima above $100 \mathrm{~mm}$. Four of the grid cells have maximum hail size equal to $250 \mathrm{~mm}$, exceeding the largest hail size reliably recorded over North America (Allen et al. 2017), with all of these observations occurring in southeastern China. The finding that the largest hail occurs along the southeastern coastline of China is similar to Allen and Allen's (2016) finding that Australia experiences the largest hail along its southeastern coastline. However, this spatial pattern differs from the continental United States, where the largest hail is found east of the Rocky Mountains, in the middle of the country, and far away from the coast (Allen et al. 2017). These climatological differences indicate potentially different physical mechanisms at work for producing extremely large hail size in these regions. Note that one hail size record with $200 \mathrm{~mm}$ was found in northeast China where convective storms with overshooting tops are frequently seen in satellite observations
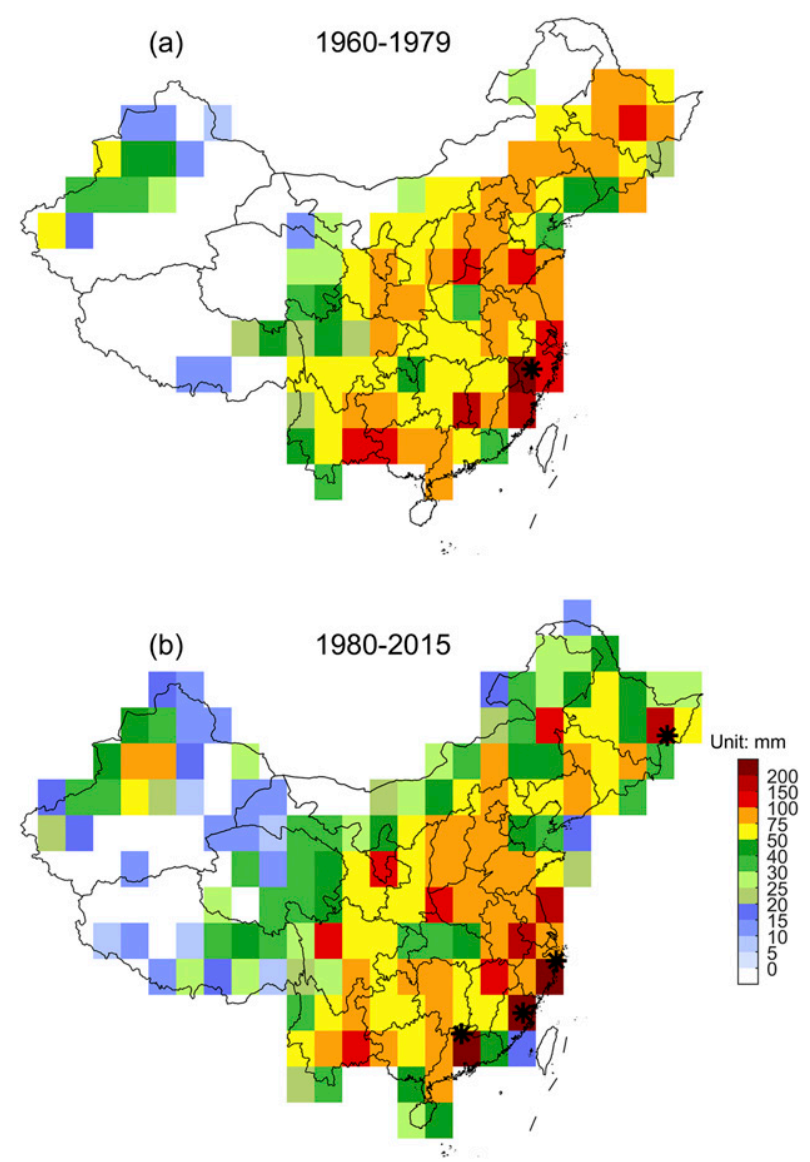

FIG. 3. Maximum hail size records during (a) 1960-79 and (b) 1980-2015. The maximum hail size was calculated using all hail size records in each grid. The star symbols indicate hail records with size between 200 and $300 \mathrm{~mm}$.

(Liu and Liu 2018). Over the TP, the maximum hail sizes are typically less than $64 \mathrm{~mm}$. However, the differences between Figs. 3a and $3 \mathrm{~b}$ (not shown) do not suggest that the spatial distributions of the maximum hail sizes have experienced significant or systematic changes over time attributable to either changes in the observational practices or changes in the density of the observation network.

While the overall maximum observed hail size provides useful information, the mean annual maximum hail size provides an understanding of the consistency of large hail occurrence (Fig. 4). Mean annual maximum hail size (i.e., annual maximum hail size averaged over the observational period) between the two periods show some changes. The differences of the spatial patterns in Figs. 3 and 4 also indicate the differences in the climatology of hail size between northern China and southern China (X. Li et al. 2018). Southern China has less frequent but larger hail size as compared to northern China. Moreover, there is no grid box in the 1980-2015 period recording mean annual maxima above $51 \mathrm{~mm}$, 

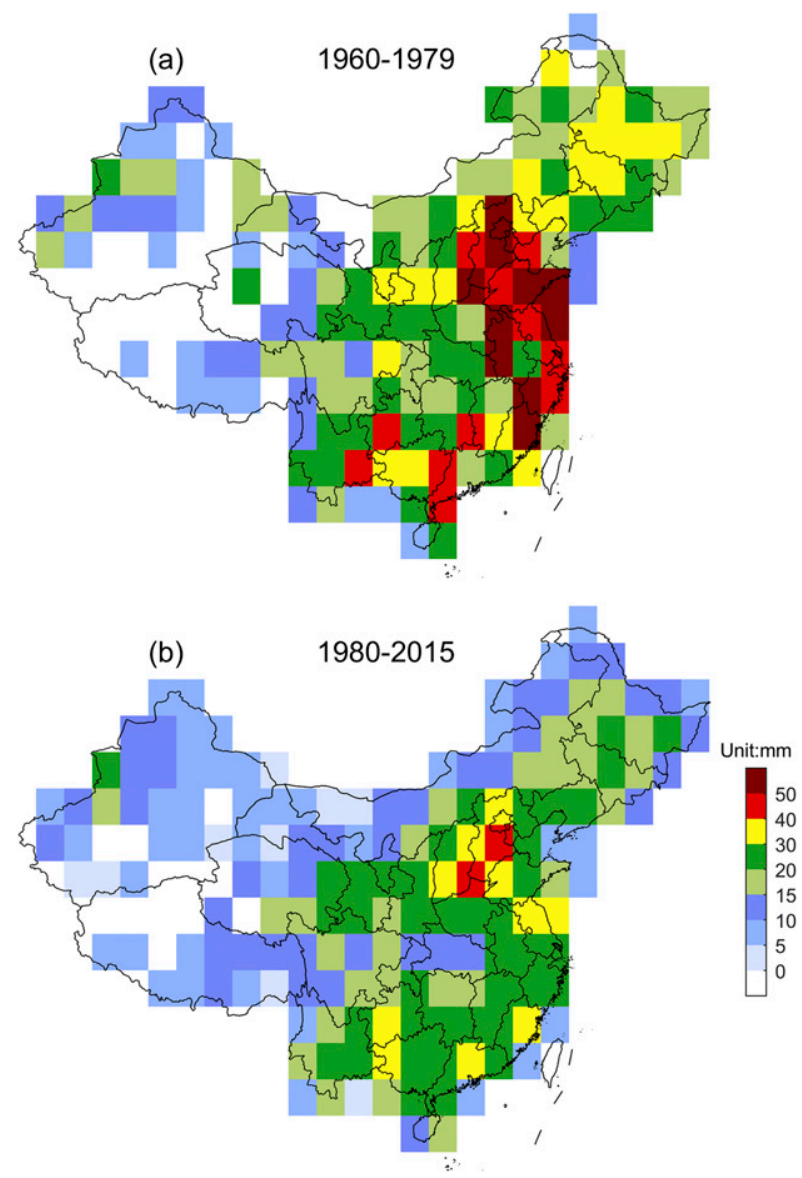

FIG. 4. Mean annual maximum hail size during (a) 1960-79 and (b) 1980-2015.

contrasting 10 grid boxes prior to 1980 . Also noticeable is the stark reduction in the number of stations recording maxima in excess of $25 \mathrm{~mm}$ between the periods. This change is particularly pronounced over northern China, where mean annual maximum hail size is between 25 and $45 \mathrm{~mm}$ during the first period but between 13 and $19 \mathrm{~mm}$ during the second period.

The seasonality of annual maxima is also of interest, particularly in the context of the results of X. Li et al. (2018), which showed no significant regional differences regarding the seasonal peak of maximum hail diameter for all observations. The average week of occurrence of the maximum hail size in any given year (Fig. 5) is more consistent with the annual cycle of hail frequency (Zhang et al. 2008). In southern China, the mean peak of maximum occurrence is as early as February and considerably earlier than anywhere else in the Northern Hemisphere (Allen et al. 2017). Similar characteristics for an early onset of the hail season are noted in subtropical regions in the Southern Hemisphere (Allen and Allen 2016; Soderholm et al. 2017). In northern China, the week of peak occurrence is predominantly during the boreal summer. The northward movement of the occurrence with time is consistent with the seasonal movement of the eastern Asian summer monsoon (EASM) and the seasonal cycle of the jet stream. It is interesting to note that the occurrence in northwest China, especially in the Xinjiang Province, is earlier than in northern China. One potential explanation for this may be that hailstorms in northwestern China are produced by frontal systems, similar to results noted for Europe (e.g., Nisi et al. 2018; Kapsch et al. 2012).

Analyzing the differences between the two periods, the annual cycle shows a moderate sensitivity to the number of records, consistent with the increasing availability of hail records in the second period (Fig. 5). The differences between the grids for the two periods indicate that the results are not spatially consistent and exhibit large grid-to-grid variability as expected of rare events (Fig. 5c). However, there is at least some indication that there may be a higher percentage of grids with earlier seasonal peak for maximum hail size in the mean (negative values) in southern China. For example, among the grid boxes with dots symbols in Fig. 5c, there are only four out of 22 grid boxes with positive values. In the grid boxes indicated with star symbols in Fig. 5c, $65 \%$ of grid boxes have positive differences, indicating a delay in seasonal peak on the order of weeks. Such a result is not unique to hail. Previous studies have shown that the precipitation in northern China and southern China have opposite trends since 1960 caused by a weakening EASM (Zhang 2015; Qian and Lin 2005). On this basis, it appears that a weakening of the EASM may also imply delays to the onset and seasonality of large hail in northern China for similar physical reasons (e.g., availability of sufficient moisture transported by the EASM).

To examine the temporal consistency of hail size observations, the annual ratio of hail size record number to the frequency of hail occurrences and the distribution of hail sizes in each year are considered (Fig. 6). This analysis reveals a sharp discontinuity for the ratio and hail size distributions occurring in the records prior to 1980. However, rather than potentially being indicative of a wholesale shift due to changes in measuring practices (e.g., Allen et al. 2017), we note that since 1980, the hail observations have included a higher percentage of hail size records. Another factor is that after 1980, hail observations were also more strictly controlled to ensure inclusion of hail size, including reports of small size hail. This is reflected by the shift in median hail size from approximately $10 \mathrm{~mm}$ in the first period to $5 \mathrm{~mm}$ after 1980. Moreover, there was a decrease of ratio during 2000-05, followed by a steady period from 2005 to 2013. 

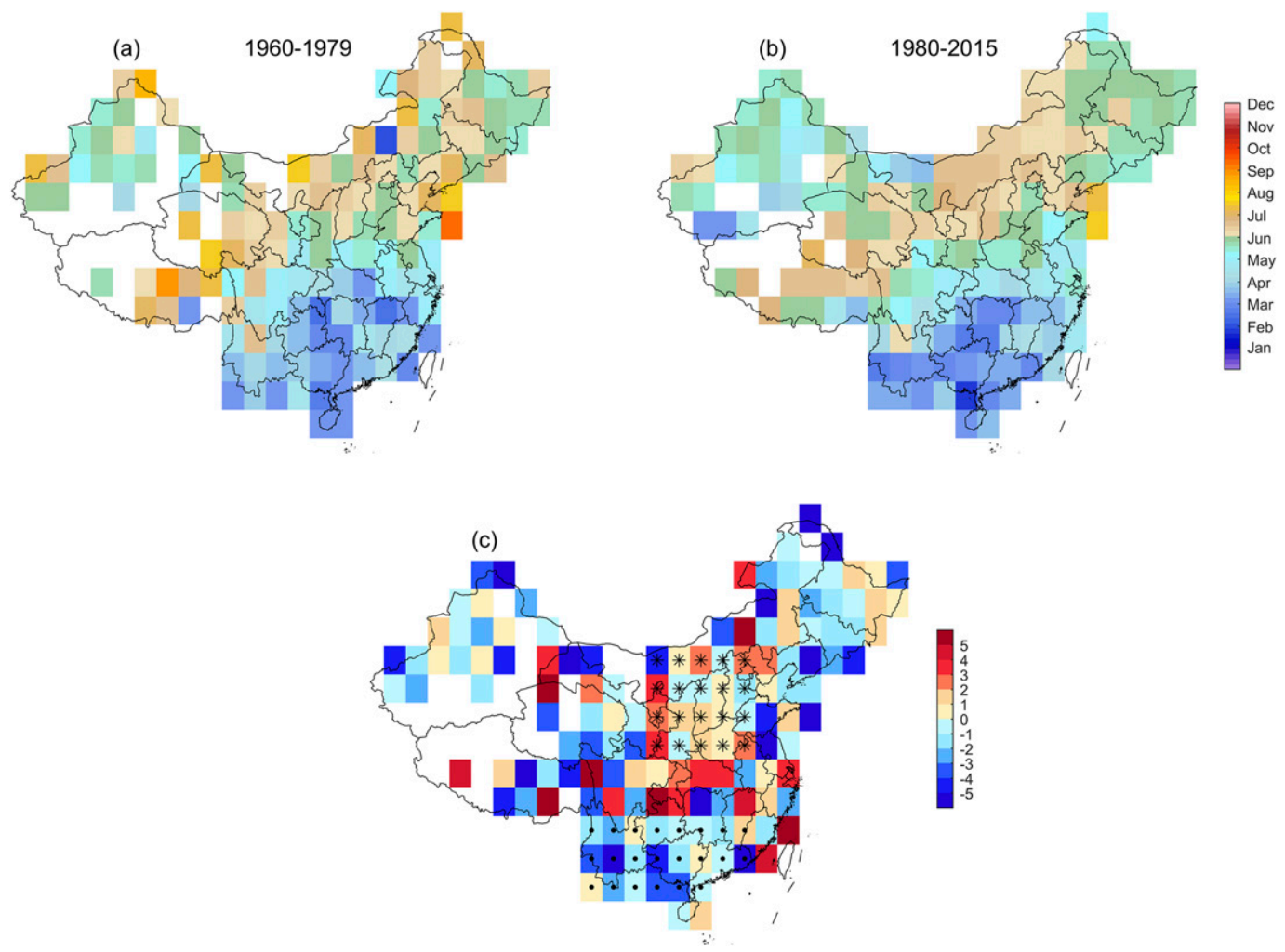

FIG. 5. Average occurrence week of annual maximum hail size during (a) 1960-79 and (b) 1980-2015, and (c) the differences between the two time periods. The dots and stars indicated southern and northern China.

Reassuringly, despite this discontinuity, median and interquartile range are consistent, except early in the record near the beginning of the 1960s, when the network was initially established. However, the shift in the extreme values is notable, indicating a decreasing frequency of extreme hailstones. In fact, for giant hail with size larger than $100 \mathrm{~mm}$ (Heymsfield et al. 2014), observations of this magnitude were only recorded before 1996. This shift is also reflected in a trend analysis of annual maximum hail size after 1980 (Fig. 7). For most grids, the annual maximum hail size shows decreasing trends, which are consistent with previous research on a station by station basis ( $\mathrm{Ni}$ et al. 2017b). The decreasing trends are larger in eastern and southern China than in the TP. A potential explanation is the sensitivity of hail to the meteorological conditions which provide moisture and the variability of aerosols in the ambient air. Thus, the decreasing trend in northern China may be tied to increasing aerosol concentrations under a continuous weaker summer EASM for recent half decade, thereby reducing the growth of large hailstones in meteorological conditions with limited moisture under heavy pollution condition (X. Li et al. 2017).

As a final analysis of the climatological characteristics, the number of years that include at least one hail observation or multiple observations are explored (Fig. 8). This is particularly important in the context of the spatial distribution of changes to the annual maxima (Fig. 7). For example, in Fig. 8, the areas along the southern coastal region do not have values because of the limited number of years with records. However, most grid boxes in eastern, central and northern China have more than 30 years of continuous

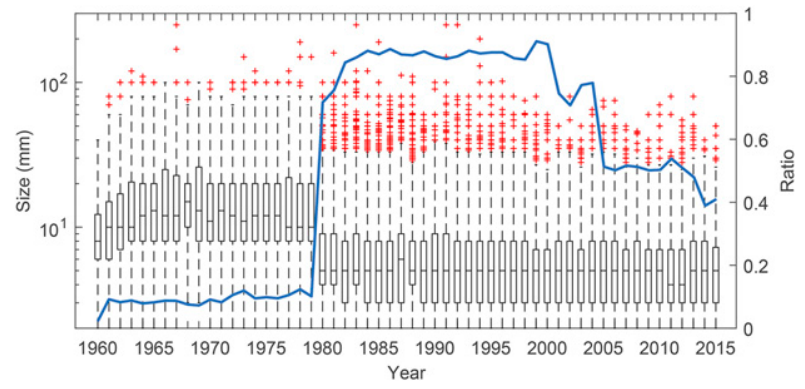

FIG. 6. Annual boxplot of hail size distributions and annual ratio (blue line). The annual ratio is the ratio of records with hail size information to records of hail occurrence from 1960 to 2015. The bottom and the top edges of each box indicate the 25 th and 75 th percentiles. The red plus signs indicate extreme values at or above 2.7 standard deviations (99.7th percentile). 


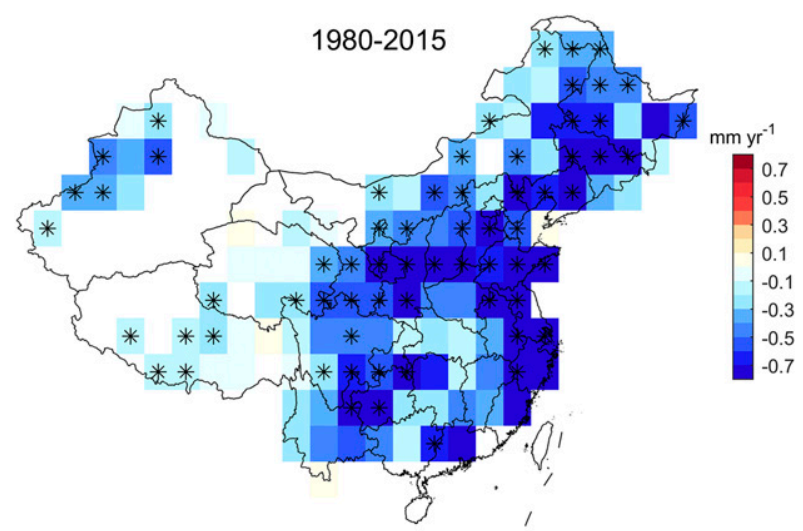

FIG. 7. Linear trends of annual maximum hail size for the period 1980-2015. The stars indicate significant trends with $p$ value less than 0.05 , which is derived from Pearson linear correlation coefficient.

observations (based on at least one hail size record per year; Fig. 8a), which is sufficient to calculate representative estimates of the Gumbel distribution parameters (Allen et al. 2017). The majority of grid boxes along the $\mathrm{TP}$, the Losses Plateau, and the Tai-hang Mountains have hail observed in every year of the 36 -yr record. For the calculation of annual maximum or annual median diameter, it is preferable to have more than one sample so that the distribution of rarer events is being captured. Therefore, in each grid, the years with at least five hail size records are shown in Fig. 8b. Most grid boxes have less than 30 years (with at least five records), except for southeastern China where some grid boxes have less than 20 years. As would be expected, the spatial patterns are highly related to the spatial distribution of hail frequency. The low frequency of hail in southeastern China leads to a lower overall number of records, despite climatologically experiencing some of the largest hail recorded. This suggests that modeling extreme values in this area will be challenging, as the increased rarity implies that any fitted distribution will be more sensitive to the record length. This further justifies the use of a coarser spatial grid $\left(2.5^{\circ}\right)$ as smaller grid resolutions such as $1^{\circ}$ would result in grid boxes with lower samples sizes for the extreme value analysis.

\section{b. Extreme value model analysis}

The time series of annual maximum hail size for the period 1980-2015 (36 years) are used to estimate the scale and location parameters of the Gumbel distribution for each grid box with at least 10 valid years (year with at least one hail size record) (Fig. 9). Consistent with the lower-frequency, large maxima, and generally midrange annual hail size, the highest values of the scale parameter
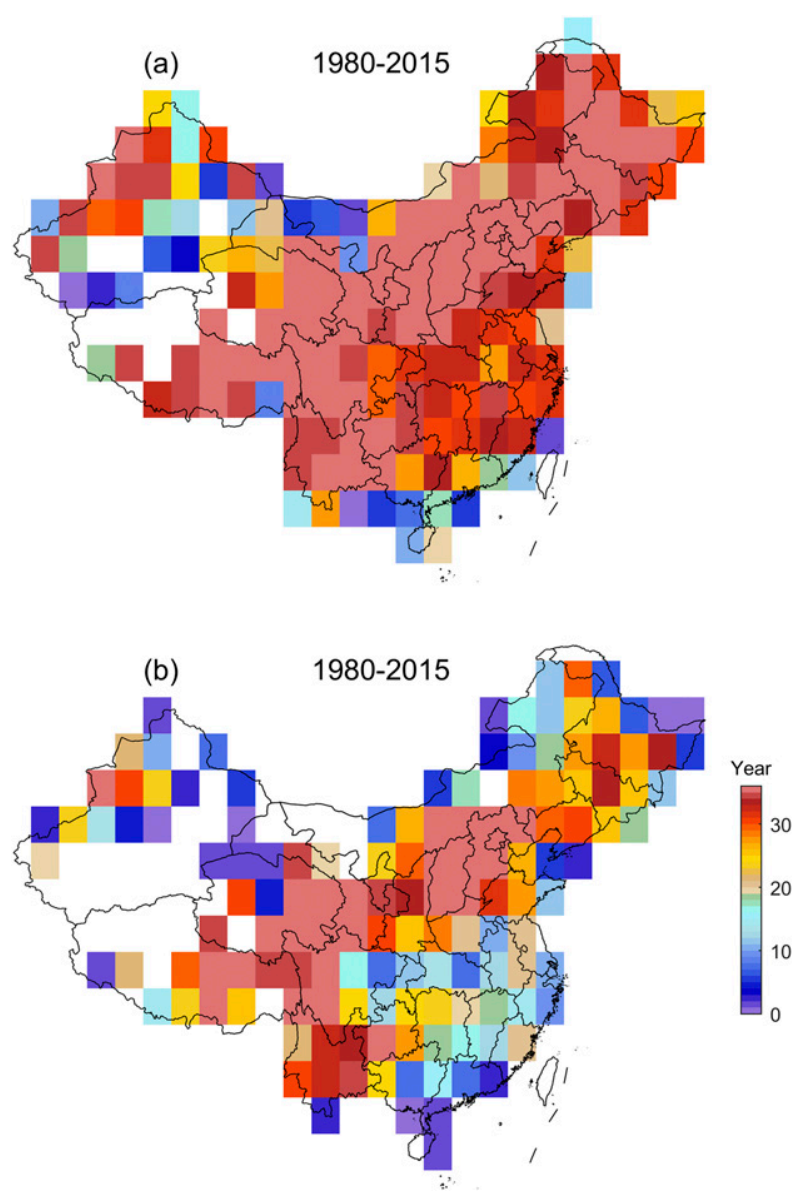

FIG. 8. Number of years (1980-2015) with (a) at least one and (b) at least five hail size records in each grid box.

are found around the lower reaches of the Yangtze River, which indicate high interannual variability in this region. The values of the scale parameter tend to decrease from east to west, with lower maximum hail diameter in the TP than in eastern China. The location parameter exhibits a similar pattern with larger values in the east and smaller values in toward the west except that for southern China and the north China plain.

To investigate the properties of the extreme value distribution, scale and location parameters were used to estimate the expected maximum hail size for a series of return periods $(5,10,20,50,100$ years, equivalent to a mean exceedance probability of $0.20,0.10,0.05,0.02$, and 0.01 in any given year). Since the observational period used in this study spans 36 years, we also calculate the expected return hail size in each grid for a $36-\mathrm{yr}$ return period to cross compare the applicability of the Gumbel model. To evaluate fit performance, we compare the observed hail and the return levels of the extreme value model (Fig. 10a). Compared with the observations (blue dots) shown in Fig. 10a, the results of 

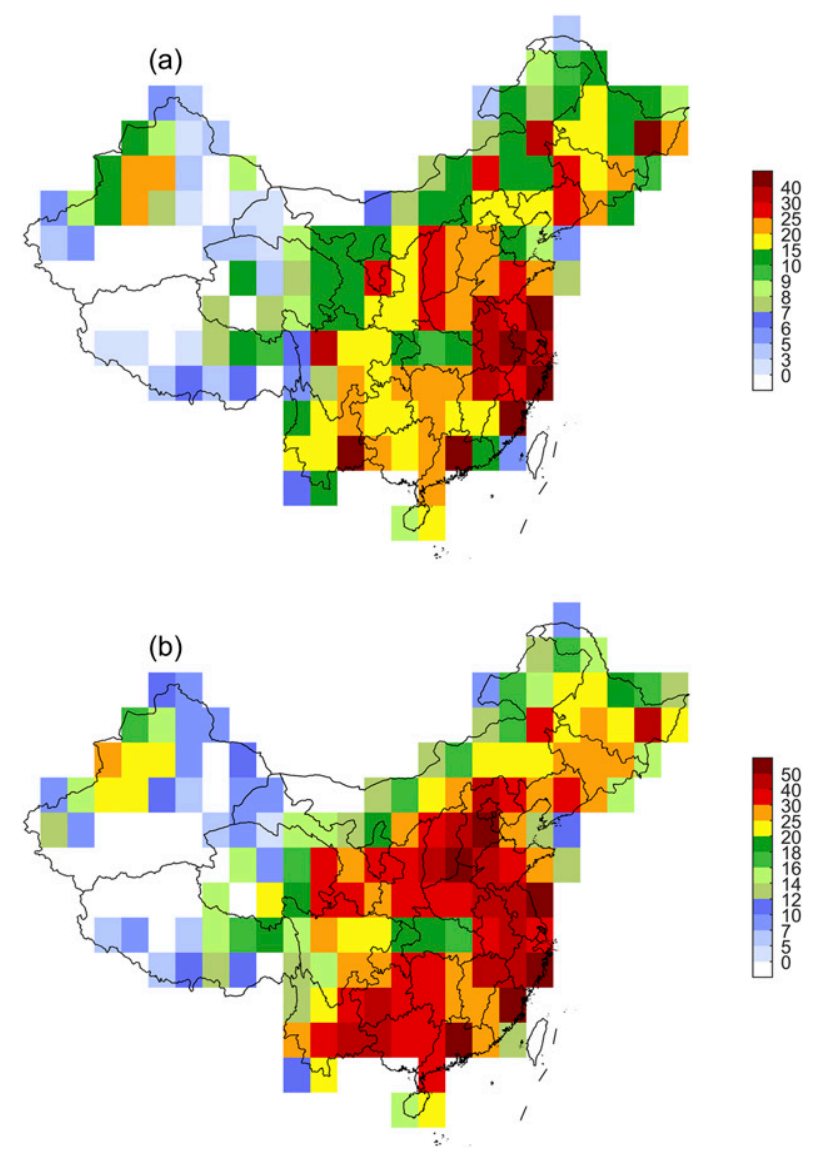

FIG. 9. Spatial distributions of the (a) scale and (b) location parameter of the Gumbel model based on the time series of annual maximum hail size for the 36-yr period 1980-2015. Grid boxes with at least 10 years of observations are considered. Note that the units of hail size are millimeter in the fitting process.

the fitted Gumbel model are generally smaller than the observations when diameters are larger than $25 \mathrm{~mm}$. However, this is not unexpected, as the fixed gridpoint observations theoretically could include rarer measurements of the expected distribution. In this specific case, the Gumbel distribution would appear to underestimate return size especially where larger observations occur. Hence, when the observed size is $100 \mathrm{~mm}$, the differences between the Gumbel model and observation are as large as $20 \mathrm{~mm}$. However, a potential source of uncertainty in the modeling approach is that the time series of samples is nonstationary and the decreasing trends of the annual maxima could result in an overestimation of return sizes.

We note that the observed hail size and the model outputs are significant linearly correlated and the linear correlation coefficient reaches 0.98 . Therefore, it is possible to adjust the model results based on the differences between the blue line and gray line shown in
Fig. 10a. The rescale process to do so would follow the formula:

$$
\begin{aligned}
\text { model }_{\text {scale }}= & \text { model }-(\text { observation } \\
& \times k+b-\text { observation }),
\end{aligned}
$$

where the $k$ and $b$ are the slope and intercept of the blue line in Fig. 10a, respectively, which are fitted using the observations. The rescaled observations (red dots) scatter around the diagonal line and have much smaller standard deviation than the direct model results, further indicating that the Gumbel distribution for this problem may underestimate the return periods of hail occurrence. However, the challenges of achieving a reliable fit means that, without further observations, it is difficult to derive the expected extreme tailing behavior.

Although the rescale process is only a simple mathematic methodology, it does allow adjustment of return size for 36-yr period closer to the observations (Figs. 10b,c), particularly for locations where there are fewer available observations, where observations are less than $25 \mathrm{~mm}$, or where larger values are not within the observed record length. Considering direct comparison between the 36-yr maxima from the observations and the model, the differences shown in Fig. 9b indicate the Gumbel model is underestimating the hail size at larger return periods. There is also a bias that is exacerbated with magnitude, with large observed maximum hail size leading to a more significant underestimate. Rescaling does not easily solve the bias of the Gumbel model as shown in Fig. 10c, as there are large regional discrepancies. Both northern and southern China are shown to be overscaled by this procedure, contrasting a persistently negative bias over the TP. Considering the rescaling process, these regional differences would be explained by the differences of maximum hail size in these regions. The larger the observed hail size, the more likely the rescaled model would overestimate the hail size. On this basis, while revealing that the Gumbel model is underestimating hail size, it is difficult to justify the rescaling of the results of the Gumbel model at each grid point given the spatial disparities in the number of observations that can be fit.

The maximum hail size for respective return periods/exceedance probabilities illustrates the expected likelihood for extreme hail over China based on the original output of the Gumbel model (Fig. 11). Significant increases in maximum hail size with decreasing exceedance probability (increasing return period) are most evident over eastern China, with a large portion of this region experiencing hail above $50 \mathrm{~mm}$ at the 10 -yr return period. Despite the lack of observations of hail in excess of $100 \mathrm{~mm}$ since 1996, the Gumbel model predicts this 


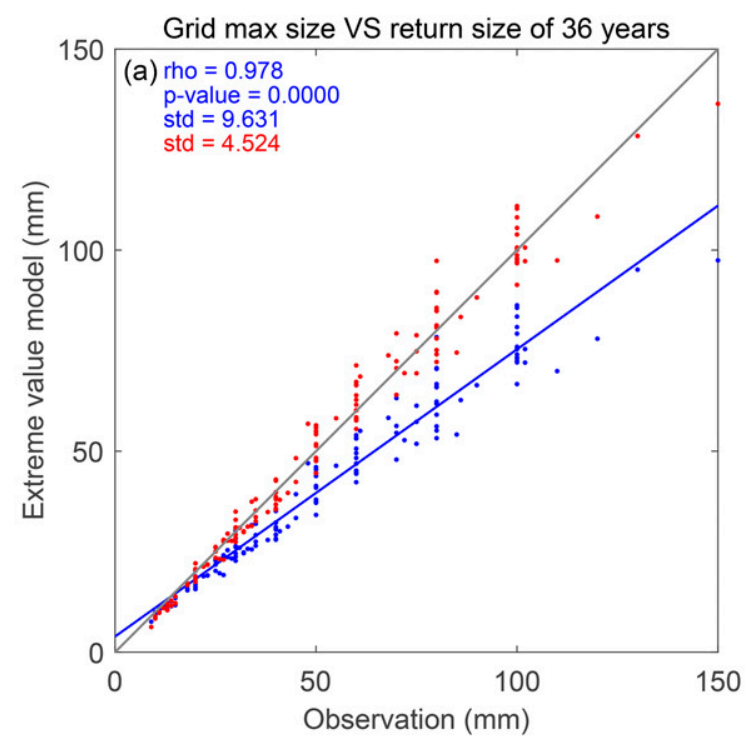

Difference between return size and observation

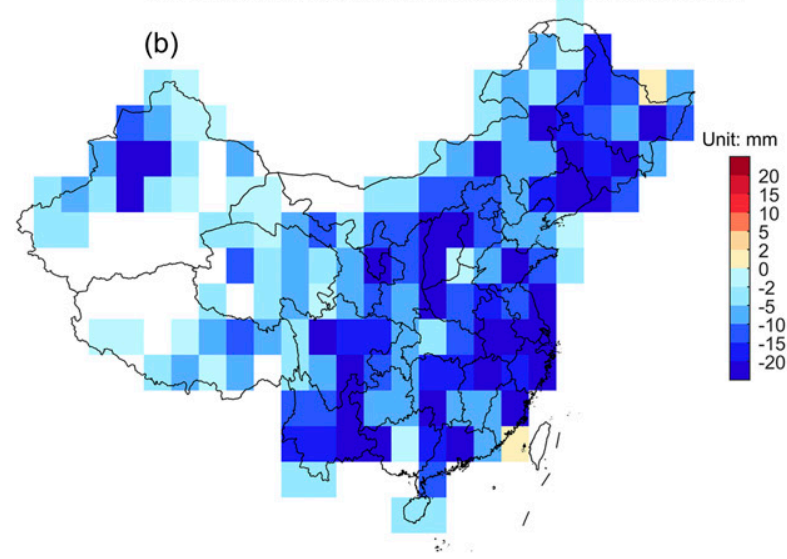

Difference between scaled return size and observation

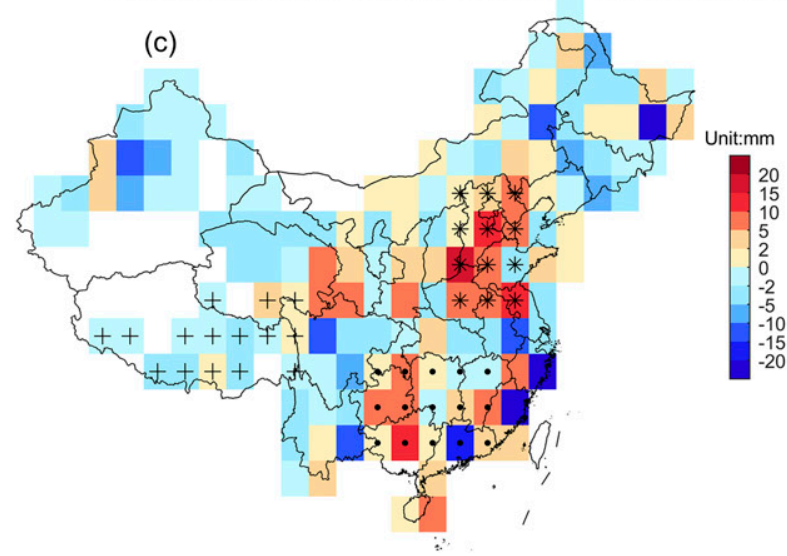

FIG. 10. (a) Observed maximum hail size during 1980-2015 and $36-y r$ return size level of maximum hail size. Each dot indicates results in one grid box. The blue dots are the return size for the 36-yr period and the red dots are the scaled return sizes; (b) spatial distributions of differences of between the 36-yr return value estimated from Gumbel model and observed maximum hail size; size hail at the 20-yr return period for a few grid boxes only, but raising to a substantial fraction at the $100-\mathrm{yr}$ return period. The TP experiences maximum hail sizes of less than $37.5 \mathrm{~mm}$ even at larger return periods up to 100 years. This paints a complex picture, as while large hail is possible but events are generally rare, hail is common in northern China but rarely as large (Zhang et al. 2008), making an understanding of the overall hazard difficult to interpret.

The hail climatology in the two periods differ as in Fig. 6 and the spatial distribution patterns of the mean annual hail size are very similar (Fig. 3). To investigate whether the performance of the Gumbel model is sensitive to the length of the observational period, the differences of return hail size for the two periods are compared (Fig. 12). The majority of grids (e.g., 55 out of 80 in Fig. 12f) in eastern China are negatively biased, which means that larger extreme hail size (for a given return period) is expected in the first period. This result is expected because the first period contains considerably more occurrences of extreme hail size compared to the second period (Fig. 6) and because there is a decreasing trend. The differences in the Fig. 12 may be caused by the data discrepancies between the two periods and hence implies the importance of quality of the hail dataset in the application of extreme value model and the desirability of an extended record length. The smaller annual mean maximum hail size in the second period also implies that the gridded return hail sizes in Fig. 11 are potentially underestimated for longer return periods (e.g., 100-yr return period) as discussed previously.

Following analysis of the gridded return values, grids marked in Fig. 10c are aggregated and used to explore the expected characteristics of the extreme value distributions regionally, denoted as the north region $(*)$, south region $(\bullet)$ and TP $(+)$, respectively. Given the regional discrepancies between the observed hail size and model results, the potential hail hazard in these different regions is also investigated. Leveraging the spread of the individual fit at each grid, the corresponding confidence was provided for each fit (Fig. 13). The TP has the smallest hail size and return levels of hail size are smaller than $37.5 \mathrm{~mm}$ even for the 100 -yr return period. This result is accompanied by high confidence in the characteristics of the fit given the narrow uncertainty bands. In contrast, the south region and the north region

(c) differences of scaled return size and observed maximum hail size; the grids with markers are denoted as the north region $(*)$, south region $(\bullet)$, and Tibetan Plateau (+), respectively. 

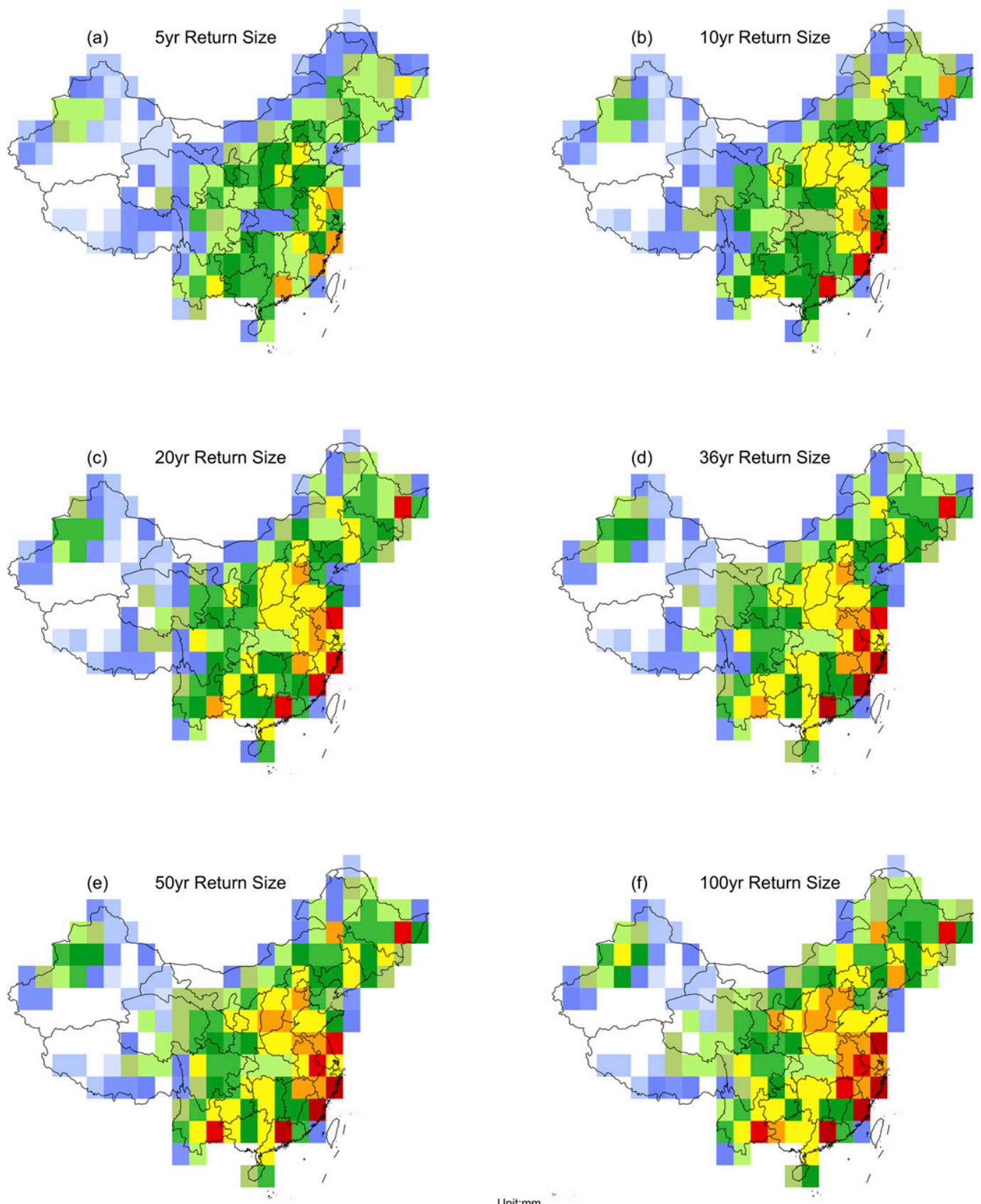

Unit:mm

$\begin{array}{lllllllllll}0 & 10 & 15 & 20 & 25 & 30 & 40 & 50 & 60 & 80 & 100150200\end{array}$

FIG. 11. Maximum hail size for return periods of (a) 5, (b) 10, (c) 20, (d) 36, (e) 50, and (f) 100 years based on observations for the period 1980-2015.

both have larger hail size than the TP. However, this leads to a greater spatial spread in the fitted characteristics. The discrepancies in Fig. 13a indicate the differences in the hail climatology between the two regions. The expected hail size of the10-yr return period is illustrative of the similarity between these regions, with 92 and $142 \mathrm{~mm}$ in the north region and the south region, respectively. The south region tends to have a higher probability of experiencing a large hail event than the north region for hailstones exceed $72 \mathrm{~mm}$. For completeness, we also compare the observations to the mean of the Gumbel distribution $(0.5772 \times$ scale + location $)$ in Fig. 13b. This comparison suggests that the Gumbel mean is somewhat positively biased and is generally 

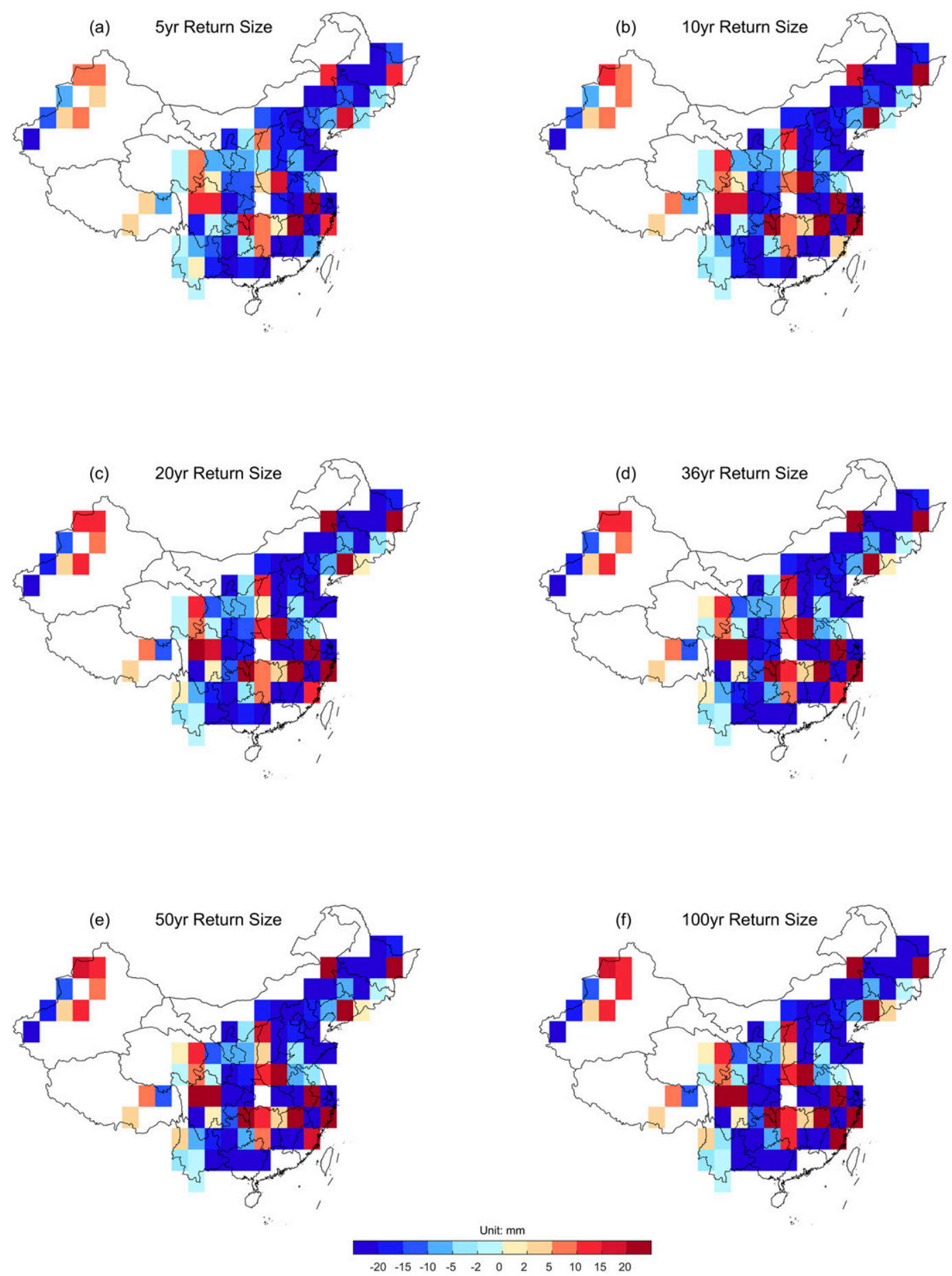

FIG. 12. Differences in maximum hail size between Gumbel model estimates based on the period 1980-2015 minus the period 1960-79 for return period of (a) 5, (b) 10, (c) 20, (d) 36, (e) 50, and (f) 100 years.

larger than the observed hail size. Comparing with the results of Allen et al. (2017), the comparison to the Gumbel mean calculated here has a greater deviation from a 1-to-1 relationship, suggested that the fit using the Gumbel extreme value model has poorer performance for China than for the United States. One potential cause of this difference may be related to the inclusion of a significant number of hail reports that are less than $19 \mathrm{~mm}$ in the model fitted here, as observation used by Allen et al. (2017) in the United States are limited to this 

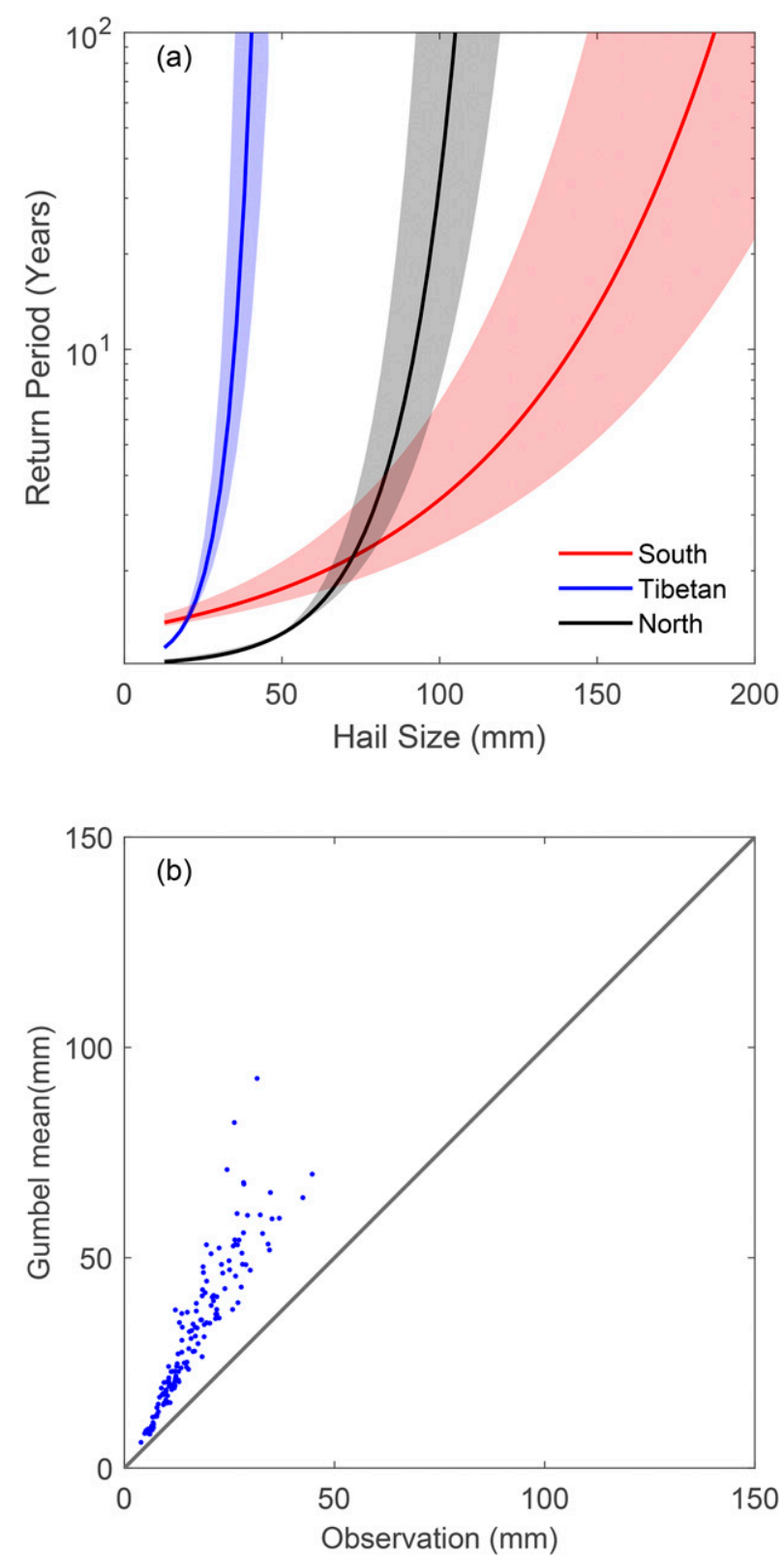

FIG. 13. (a) The relationship between hail size and return periods in different regions shown as in Fig. 10c. The boundaries of the filled area indicated the $95 \%$ confidence intervals. (b) Observed annual mean maximum hail size in each grid and corresponding Gumbel mean. The results are derived using observations between 1980 and 2015.

threshold at the least. Alternatively, it is plausible that the nature of the observation stations as opposed to a public sourced reporting dataset yields a very different picture of the distribution that is more representative of the probability at fixed locations like hail pads. Another possibility is that this result is simply a reflection of the lower frequency at which severe hailstorms occur in
China, relative to the United States (Brooks et al. 2003; Zipser et al. 2006). It should also be noted that the return period estimation is quite sensitive to the inclusion of giant hailstones. In the south region, there is one grid box (Fig. 3) which contains one observation of $250 \mathrm{~mm}$. If this record was not considered in the model, the return period does shift significantly toward the smaller hail size ranges. For example, without this $250 \mathrm{~mm}$ size hailstone in the south region, the expected hail return size at the 10 -yr return period drops from 142 to $94 \mathrm{~mm}$. Thus caution should be taken in inferring results where such extremely large hailstones (e.g., $>200 \mathrm{~mm}$ ) are observed, similar to the contribution of the Vivian, South Dakota, hailstone $(200 \mathrm{~mm})$ to the return intervals in the United States (Allen et al. 2017).

Another consideration is the size of the grid used for spatially aggregating hail observations. Here we utilize a $2.5^{\circ}$ grid to encompass several stations for each observation, yet clearly these are wide areas over which a hailstorm could be expected, inferring a lower local probability. In the discussion of Fraile et al. (2003), it was noted that the relationship between maximum hail size and return period are highly related to the hail pad density. With increasing station density, the return period for a certain maximum hailstone diameter would potentially decrease. As shown in Fig. 2, the weather station density varies significantly within the various regions, which may influence the relationship in Fig. 13. It is also plausible that, at least locally, the probability of hail might be higher, or could be higher at places away from the fixed sites at which observations are taken. Nevertheless, there are also discrepancies between hail pad stations and weather stations. Hail pads only record hailstones impacting the pad (typically not exceeding $0.3 \times 0.3 \mathrm{~m}^{2}$ in area), whereas trained observers at weather stations have the capacity to observe hailstones over a wider area and hailstones found in the same administrative region could also be reported by the public and newspapers. Indeed, Smith and Waldvogel (1989) found systematically larger hailstones on the ground around the hail pads, reflecting the random aspects, low density of hailfall, and potential underestimation of maximum hail size by hail pad observations relative to hail reports. Although Bardsley (1990) suggested using extreme value theory to build a relationship of hail pad maxima to real maxima, there remains uncertainty caused by the representativeness problems of the hail pad observations. An advantage of the dataset used here is that monthly weather reports at weather stations also include severe hailstone that happened 
in the same administrative region, thus providing a more complete record of maximum hail size. Considering these factors, we suggest that the influences of weather station density on the return periods would be less significant than those of hail pad station density on return levels such as those noted by Fraile et al. (2003).

\section{Conclusions}

A $2.5^{\circ}$ gridded climatology of hail size has been derived from an archive of long-term observations at 2254 stations in China for the period 1960-2015. This archive provides a useful dataset to explore comparisons to other regions around the globe and for developing statistical relationships between environmental variables to hail size. However, the record is affected by discontinuities, as reflected by the change in observations at 1980 , when the observation regulation at weather stations caused a sharp change of hail size percentiles. To overcome this limitation, results were presented separately for two time periods. Using the dataset since 1980, a Gumbel extreme value model was applied at each grid box to explore the spatial distribution patterns of maximum hail size for different return periods. At the 20 -yr return period, most grid boxes in eastern China were expected to experience $\geq 51 \mathrm{~mm}$ hail, while for periods longer than 36 years, several grid boxes would be expected to experience a hailstone larger than $127 \mathrm{~mm}$. A simple rescaling process was used to evaluate the performance of the Gumbel model for the 36-yr return period. The result of the rescaling process implies that the Gumbel model may underestimate the maximum hail size, but this result is uncertain due to the potential effects of nonstationarities in the observed hail size records and decreasing hail size trend over time.

Regionally, the expected maximum hail size for a certain return period exhibits large variations, thereby reflecting the diverse set of climatological characteristics for hail across China (Li et al. 2016). Specifically, this led to the consideration of the TP, north region, and south region separately to highlight these climatological differences. As would be expected given the high elevation and comparatively low instability and moisture content, the TP is found with smallest expected maximum hail size, and the consistency and continuity of observational records suggest high confidence in this result. This is consistent with the hail size spectra discussed by $\mathrm{Ni}$ et al. (2017b). These results suggested that in weather stations higher than $2000 \mathrm{~m}$, the hail size spectra were closer to an exponential distribution, while in regions lower than $2000 \mathrm{~m}$, the hail size spectra were closer to a gamma distribution. However, differences between the south region and the north region are found to be more complicated. The south region experiences hail infrequently, but when hail does occur it tends to be large. In contrast, the north region experiences hail more frequently, but with lower maximum hail size. While the differences between the north region and the south region are consistent with the regional environmental differences characterized by Li et al. (2016) and Liu and Tang (1966), it is not clear that the potential maximum hail size should have this type of difference, particularly considering the greater underestimation of hail size over the north if the full period record is considered. Hence, large hail may be experienced in this region at similar intervals, but it may be uncaptured by the existing observational record. Given these regional differences, we surmise that the simple assumption of Gumbel distribution may lead to unexpected distributional errors in the extreme value model output.

In comparison to Allen et al. (2017)'s work in the United States, the Gumbel mean in this study was found to differ more from observations. Consistent with Allen et al. (2017), however, was the finding that the model underestimated maximum hail size. This difference may be driven by limited records of hail size observations in China, especially for large hail. As discussed in Fig. 8, although most grids have at least one hail size record for more than 30 years, almost half of the grid boxes have only 5 records for less than 20 years, suggesting that the hazard may be underestimated due to a lack of observations. Further, the number of large hail ( $\geq 20 \mathrm{~mm})$ is not comparable with the observation in United States. In average, there are 93 large size hail reports per year during 1980-2015. The limited hail size record makes the grid boxes much coarser than the results of Allen et al. (2017), resulting in the lack of results at finer spatial resolution. It should also be noted that considered in the bulk distribution, hail sizes in China are typically smaller than in the United States, while the U.S. hail dataset rarely includes hail sizes less than $19 \mathrm{~mm}$. This is reflected by the fact that in the majority of grid boxes, the maximum hail size is less than $100 \mathrm{~mm}$, while the annual mean is generally smaller than $51 \mathrm{~mm}$, significantly smaller than the widespread observations of $102-107 \mathrm{~mm}$ recorded over the United States, and means exceeding $51 \mathrm{~mm}$.

This study reveals the occurrence probability of extreme hail size, which is based on the past observations and the stationarity assumption common to many extreme value models. However, how the underlying hail size climatology will change under the context of climate change is still a controversial topic, because 
of the complex impacts of competing environmental parameters on hailstorms (Allen et al. 2020). For example, a number of studies have pointed to the rising freezing level height being a significant contributor to the melting of smaller hailstones, for example as has been shown over Colorado, China, and southwestern France (Dessens et al. 2015; Mahoney et al. 2012; Xie et al. 2010). However, it is not clear whether melting is significant for larger hail sizes (e.g., Trapp et al. 2019; Brimelow et al. 2017). As a large-scale environmental background, the EASM also plays a crucial role in hail climatology, by regulating the variations of environmental parameters like precipitable water (PW), vertical wind shear (VWS), convective available potential energy (CAPE) etc. (M. Li et al. 2018; Zhang et al. 2017). The various combinations of these parameters lead to different hail size climatology. For example, large VWS and PW favor the large hail in South China (M. Li et al. 2018). With a weakened EASM in the recent decades, the northward water vapor transportation was found to decrease over most region of China (Zhang et al. 2017), which will lead to a corresponding reduction in the favorable moisture conditions leading to severe hailstorms. Moreover, the impacts of aerosols and moisture on hail precipitation rate are highly nonlinear, although the relation between precipitation rate hail size is still of uncertainty (M. Li et al. 2017; X. Li et al. 2017). For example, hail precipitation increases with cloud condensation nuclei concentrations (CCNC) under certain CCNC threshold and decreases with CCNC above the CCNC threshold. These complex factors make it difficult to attribute the cause of changes in the climatology of hail size. Moreover, the scale and microphysics sensitivity in both numeric and environmental approaches to explain the changes of hail climatology have made slow progress because of the lack of an easy way to parameterize hail. Thus, a future avenue for exploring potential changes in the hail size climatology is to environmentally parameterize the model applied here and extrapolate future occurrence probabilities of extreme hail size.

In future work, the gridded hail size dataset developed herein will be used to explore relationships to favorable environments derived from reanalysis or climate model output. Some of the potential applications include exploring climate variability. For example, Allen et al. (2015b) investigated the influence of ENSO on hail frequency using environmental proxies. Similar approaches have also considered the global occurrence of hail in excess of $25 \mathrm{~mm}$. For example, Prein and Holland (2018) showed that four predictors could discriminate large hail frequencies for several different regions. This dataset will also allow comparison to remotely sensed observations, for example satellite-derived proxies which also provide observations of hail worldwide (Bang and Cecil 2019; Cecil and Blankenship 2012; Ni et al. 2017a). Provided that it can be validated that the hail occurrence ratio between two regions from satellite is consistent with surface-observed hail occurrence, it is reasonable to expect that these regional analyses can be used to better inform the global climatology constructed from satellites for larger hailstones, and in doing so provide a better basis for a remotely sensed global hail climatology.

Acknowledgments. We are grateful for Dr. Xiaofei Li's help in the data preparation. This study was supported by the Chinese National Science Foundation (Grant 41875052) and supported by Fundamental Research Funds for the Central Universities (SWU118132). X. N. is also supported by the Grants Program for Chongqing's Scholars with Overseas Experience (cx2019042). J. F. acknowledges the support of the U.S. Department of Energy Early Career Award Program.

\section{REFERENCES}

Allen, J. T., and E. R. Allen, 2016: A review of severe thunderstorms in Australia. Atmos. Res., 178-179, 347-366, https:// doi.org/10.1016/j.atmosres.2016.03.011.

, M. K. Tippett, and A. H. Sobel, 2015a: An empirical model relating U.S. monthly hail occurrence to large-scale meteorological environment. J. Adv. Model. Earth Syst., 7, 226-243, https://doi.org/10.1002/2014MS000397.

,$- \ldots$, and $-2015 \mathrm{~b}$ : Influence of the El Niño/Southern Oscillation on tornado and hail frequency in the United States. Nat. Geosci., 8, 278-283, https://doi.org/10.1038/ngeo2385.

- - Y. Y. Kaheil, A. H. Sobel, C. Lepore, S. Nong, and A. Muehlbauer, 2017: An extreme value model for U.S. hail size. Mon. Wea. Rev., 145, 4501-4519, https://doi.org/10.1175/ MWR-D-17-0119.1.

_ I. M. Giammanco, M. R. Kumjian, H. J. Punge, Q. Zhang, P. Groenemeijer, M. Kunz, and K. Ortega, 2020: Understanding hail in the earth system. Rev. Geophys., 58, e2019RG000665, https://doi.org/10.1029/2019RG000665.

American Meteorological Society, 2012: Hail. Glossary of Meteorology, http://glossary.ametsoc.org/wiki/Hail.

Bang, S. D., and D. J. Cecil, 2019: Constructing a multifrequency passive microwave hail retrieval and climatology in the GPM domain. J. Appl. Meteor. Climatol., 58, 1889-1904, https:// doi.org/10.1175/JAMC-D-19-0042.1.

Bardsley, W. E., 1990: On the maximum observed hailstone size. J. Appl. Meteor., 29, 1185-1187, https://doi.org/10.1175/ 1520-0450(1990)029<1185:OTMOHS > 2.0.CO;2.

Berthet, C., E. Wesolek, J. Dessens, and J. L. Sanchez, 2013: Extreme hail day climatology in Southwestern France. Atmos. Res., 123, 139-150, https://doi.org/10.1016/j.atmosres.2012.10.007.

Brimelow, J. C., W. R. Burrows, and J. M. Hanesiak, 2017: The changing hail threat over North America in response to anthropogenic climate change. Nat. Climate Change, 7, 516-522, https://doi.org/10.1038/nclimate3321. 
Brooks, H. E., J. W. Lee, and J. P. Craven, 2003: The spatial distribution of severe thunderstorm and tornado environments from global reanalysis data. Atmos. Res., 67-68, 73-94, https:// doi.org/10.1016/S0169-8095(03)00045-0.

Cao, Z., 2008: Severe hail frequency over Ontario, Canada: Recent trend and variability. Geophys. Res. Lett., 35, L14803, https:// doi.org/10.1029/2008GL034888.

Cecil, D. J., and C. B. Blankenship, 2012: Toward a global climatology of severe hailstorms as estimated by satellite passive microwave imagers. J. Climate, 25, 687-703, https://doi.org/ 10.1175/JCLI-D-11-00130.1.

Changnon, D., S. A. Changnon, and S. S. Changnon, 2001: A method for estimating crop losses from hail in uninsured periods and regions. J. Appl. Meteor., 40, 84-91, https://doi.org/10.1175/15200450(2001)040<0084:AMFECL > 2.0.CO;2.

Chinese Meteorological Administration, 2007: Specifications for Surface Meteorological Observation. Part 4: Observation of Weather Phenomenon. China Meteorological Press, 16 pp.

Coles, S., 2001: An Introduction to Statistical Modelling of Extreme Values. Springer, 209 pp.

Dessens, J., C. Berthet, and J. L. Sanchez, 2015: Change in hailstone size distributions with an increase in the melting level height. Atmos. Res., 158-159, 245-253, https://doi.org/10.1016/ j.atmosres.2014.07.004.

Ferraro, R., J. Beauchamp, D. Cecil, and G. Heymsfield, 2015: A prototype hail detection algorithm and hail climatology developed with the Advanced Microwave Sounding Unit (AMSU). Atmos. Res., 163, 24-35, https://doi.org/10.1016/ j.atmosres.2014.08.010.

Fraile, R., C. Berthet, J. Dessens, and J. L. Sánchez, 2003: Return periods of severe hailfalls computed from hailpad data. Atmos. Res., 67-68, 189-202, https://doi.org/10.1016/S0169-8095(03) 00051-6.

Guan, Y., F. Zheng, P. Zhang, and C. Qin, 2014: Spatial and temporal changes of meteorological disasters in China during 1950-2013. Nat. Hazards, 75, 2607-2623, https://doi.org/ 10.1007/s11069-014-1446-3.

Heymsfield, A. J., I. M. Giammanco, and R. Wright, 2014: Terminal velocities and kinetic energies of natural hailstones. Geophys. Res. Lett., 41, 8666-8672, https://doi.org/10.1002/ 2014GL062324.

Jenkinson, A. F., 1955: The frequency distribution of annual maximum (or minimum) values of meteorological elements. Quart. J. Roy. Meteor. Soc., 81, 158-171, https://doi.org/ 10.1002/QJ.49708134804.

Kapsch, M. L., M. Kunz, R. Vitolo, and T. Economou, 2012: Longterm trends of hail-related weather types in an ensemble of regional climate models using a Bayesian approach. J. Geophys. Res., 117, D15107, https://doi.org/10.1029/2011JD017185.

Li, M., Q. Zhang, and F. Zhang, 2016: Hail day frequency trends and associated atmospheric circulation patterns over China during 1960-2012. J. Climate, 29, 7027-7044, https://doi.org/ 10.1175/JCLI-D-15-0500.1.

_- F. Zhang, Q. Zhang, J. Y. Harrington, and M. R. Kumjian, 2017: Nonlinear response of hail precipitation rate to environmental moisture content: A real case modeling study of an episodic midlatitude severe convective event. J. Geophys. Res. Atmos., 122, 6729-6747, https://doi.org/10.1002/2016JD026373.

, D. L. Zhang, J. Sun, and Q. Zhang, 2018: A statistical analysis of hail events and their environmental conditions in China during 2008-15. J. Appl. Meteor. Climatol., 57, 2817-2833, https://doi.org/10.1175/JAMC-D-18-0109.1.
Li, X., Q. Zhang, and H. Xue, 2017: The role of initial cloud condensation nuclei concentration in hail using the WRF NSSL 2-moment microphysics scheme. Adv. Atmos. Sci., 34, 11061120, https://doi.org/10.1007/s00376-017-6237-9.

- - - T. Zou, J. Lin, H. Kong, and Z. Ren, 2018: Climatology of hail frequency and size in China, 1980-2015. J. Appl. Meteor. Climatol., 57, 875-887, https://doi.org/ 10.1175/JAMC-D-17-0208.1.

Liu, N., and C. Liu, 2018: Synoptic environments and characteristics of convection reaching the tropopause over northeast China. Mon. Wea. Rev., 146, 745-759, https://doi.org/10.1175/ MWR-D-17-0245.1.

Liu, Q. G., and M. C. Tang, 1966: Climatological characteristics of hail in China (in Chinese). Acta Geogr. Sin., 32, 48-65.

Mahoney, K., M. Alexander, G. Thompson, J. J. Barsugli, and J. D. Scott, 2012: Changes in hail and flood risk in high-resolution simulations over Colorado's mountains. Nat. Climate Change, 2, 125-131, https://doi.org/10.1038/nclimate1344.

Ministry of Civil Affairs of the PRC, 2016: Hailstorm caused more than 400 million Yuan direct economic loss in the Northern China (in Chinese). Accessed 12 September 2016, http:/ www.mca.gov.cn/article/xw/zqkb/201609/20160915001768.shtml.

Ni, X., C. Liu, D. J. Cecil, and Q. Zhang, 2017a: On the detection of hail using satellite passive microwave radiometers and precipitation radar. J. Appl. Meteor. Climatol., 56, 2693-2709, https://doi.org/10.1175/JAMC-D-17-0065.1.

—, Q. Zhang, C. Liu, X. Li, T. Zou, J. Lin, H. Kong, and Z. Ren, 2017b: Decreased hail size in China since 1980. Sci. Rep., 7, 10913, https://doi.org/10.1038/s41598-017-11395-7.

Nisi, L., A. Hering, U. Germann, and O. Martius, 2018: A 15-year hail streak climatology for the Alpine region. Quart. J. Roy. Meteor. Soc., 144, 1429-1449, https:// doi.org/10.1002/QJ.3286.

Palutikof, J. P., B. B. Brabson, D. H. Lister, and S. T. Adcock, 1999: A review of methods to calculate extreme wind speeds. Meteor. Appl., 6, 119-132, https://doi.org/10.1017/ S1350482799001103.

Pavia, E. G., and J. J. O'Brien, 1986: Weibull statistics of wind speed over the ocean. J. Climate Appl. Meteor., 25, 1324-1332, https://doi.org/10.1175/1520-0450(1986)025<1324:WSOWSO> 2.0.CO;2.

Prein, A. F., and G. J. Holland, 2018: Global estimates of damaging hail hazard. Wea. Climate Extremes, 22, 10-23, https://doi.org/ 10.1016/j.wace.2018.10.004.

Punge, H. J., and M. Kunz, 2016: Hail observations and hailstorm characteristics in Europe: A review. Atmos. Res., 176-177, 159-184, https://doi.org/10.1016/j.atmosres.2016.02.012.

Qian, W., and X. Lin, 2005: Regional trends in recent precipitation indices in China. Meteor. Atmos. Phys., 90, 193-207, https:// doi.org/10.1007/s00703-004-0101-z.

Smith, P. L., and A. Waldvogel, 1989: On determinations of maximum hailstone sizes from hailpad observations. J. Appl. Meteor., 28, 71-76, https://doi.org/10.1175/1520-0450(1989) 028<0071:ODOMHS $>2.0$. CO;2.

Soderholm, J. S., H. McGowan, H. Richter, K. Walsh, T. M. Weckwerth, and M. Coleman, 2017: An 18-year climatology of hailstorm trends and related drivers across southeast Queensland, Australia. Quart. J. Roy. Meteor. Soc., 143, 1123-1135, https://doi.org/10.1002/QJ.2995.

Towery, N. G., G. M. Morgan, and S. A. Changnon, 1976: Examples of the wind factor in crop-hail damage. J. Appl. Meteor., 15, 1116-1120, https://doi.org/10.1175/1520-0450(1976) 015<1116:EOTWFI > 2.0.CO;2. 
Trapp, R. J., K. A. Hoogewind, and S. Lasher-Trapp, 2019: Future changes in hail occurrence in the United States determined through convection-permitting dynamical downscaling. J. Climate, 32, 5493-5509, https://doi.org/10.1175/JCLI-D-18-0740.1.

Xie, B., Q. Zhang, and Y. Wang, 2010: Observed characteristics of hail size in four regions in China during 1980-2005. J. Climate, 23, 4973-4982, https://doi.org/10.1175/2010JCLI3600.1.

Xu, J., 1983: Some hail research in China. Bull. Amer. Meteor. Soc., 64, 124-132, https://doi.org/10.1175/1520-0477(1983)064<0124 SHRIC $>2.0 . C O ; 2$.

Yue, Y., L. Zhou, A.-X. Zhu, and X. Ye, 2019: Vulnerability of cotton subjected to hail damage. PLOS ONE, 14, e0210787, https://doi.org/10.1371/journal.pone.0210787.
Zhang, C., Q. Zhang, and Y. Wang, 2008: Climatology of hail in China: 1961-2005. J. Appl. Meteor. Climatol., 47, 795-804, https://doi.org/10.1175/2007JAMC1603.1.

Zhang, Q., X. Ni, and F. Zhang, 2017: Decreasing trend in severe weather occurrence over China during the past 50 years. Nat. Sci. Rep., 7, 42310, https://doi.org/10.1038/SREP42310.

Zhang, R., 2015: Changes in East Asian summer monsoon and summer rainfall over eastern China during recent decades. Sci. Bull., 60, 1222-1224, https://doi.org/10.1007/s11434-015-0824-x.

Zipser, E. J., D. J. Cecil, C. Liu, S. W. Nesbitt, and D. P. Yorty, 2006: Where are the most intense thunderstorms on Earth? Bull. Amer. Meteor. Soc., 87, 1057-1072, https://doi.org/ 10.1175/BAMS-87-8-1057. 